Research Article

\title{
Pressure Relief Mechanism of Directional Hydraulic Fracturing for Gob-Side Entry Retaining and Its Application
}

\author{
Zhang Xiao $\mathbb{D}^{1,2}$ and Kang Hongpu ${ }^{1,2}$ \\ ${ }^{1}$ Coal Mining and Design Branch, China Coal Research Institute, Beijing 100013, China \\ ${ }^{2}$ Coal Mining and Design Department, Tiandi Science \& Technology Co., Ltd., Beijing 100013, China
}

Correspondence should be addressed to Zhang Xiao; 611454449@qq.com

Received 31 December 2020; Revised 18 February 2021; Accepted 13 March 2021; Published 12 April 2021

Academic Editor: Guangchao Zhang

Copyright (c) 2021 Zhang Xiao and Kang Hongpu. This is an open access article distributed under the Creative Commons Attribution License, which permits unrestricted use, distribution, and reproduction in any medium, provided the original work is properly cited.

\begin{abstract}
In order to make clear the pressure relief mechanism and application effect of directional hydraulic fracturing for gob-side entry retaining, the directional hydraulic fracturing was carried out by $400 \mathrm{~m}$ in haulage gateway remaining along the goaf in 50108 working face of Hejiata Coal Mine. Taking this as the engineering background, a mechanical model of roof cutting was established and the pressure relief mechanism was clarified. The theoretical research shows that it is the moments of gravity $F_{\mathrm{G}}$ of the curved triangular roof plate at the face end, the pressure $q$ of the overlying soft rock, and the transverse force $T_{\mathrm{CB}}$ in the "voussoir beam" structure to the left endpoint of the triangular block, that is, $M_{F_{\mathrm{G}}}, M_{q}$, and $M_{T_{\mathrm{CB}}}$, which determines the roadside supporting resistance. Hydraulic fracturing can reduce the lateral cantilever length of the basic roof, thus greatly reducing the values of $M_{F_{\mathrm{G}}}$, $M_{T_{\mathrm{CB}}}$, and $M_{q}$, and significantly reduce the roadside supporting resistance. The field test shows that the directional hydraulic fracturing technology can effectively improve the stress environment of the face end and reduce the deformation of the roadway, and it has a good application effect on the gob-side entry retaining.
\end{abstract}

\section{Introduction}

The gob-side entry retaining technology can eliminate the section coal pillars and increase the coal recovery rate, reduce the number of roadways and the mine excavation rate, and realize $Y$-shaped ventilation in the mining face, which is beneficial to solve the gas problem. However, the roadway remaining along the goaf is affected by the mining of two working faces. It is affected by the violent rock activity in the goaf area of the upper section working face and also affected by the abutment pressure of the working face of the lower section. Both the roof and two sides of the roadway are severely deformed, along with the bottom drum, and it is difficult to maintain the roadway [1-5].

Roadway pressure relief technology can achieve the purpose of pressure relief by changing the integrity and continuity of the surrounding rock. Commonly used pressure relief methods are blasting and hydraulic fracturing [6-8]. Due to potential safety hazards in explosive blasting, its use in coal mines is strictly controlled. In recent years, hydraulic fracturing, as a safe, simple, and economical technology, has been increasingly used in coal mines. At present, hydraulic fracturing is widely used in the weakening of the hard roof [9-11], and there are few studies on its application in the gobside entry retaining. In this paper, taking the 50108 working face of Hejiata Coal Mine as the engineering background, the hydraulic fracturing technology is used in the gob-side entry retaining and a roof mechanical model is established to clarify the pressure relief mechanism. The theory and field practice show that hydraulic fracturing technology can effectively alleviate the pressure of the roadway and performs well in retaining the roadway along the goaf. 


\section{Mechanical Model of the Roof in Gob-Side Entry Retaining}

2.1. Mechanical Model of the Roof. After excavation, with the advance of the working face, the " $O-X$ " type fracture occurs in the basic roof [12]. The basic roof will form a curved triangular plate structure (key block B) at the face end and an inverted trapezoidal structure (key block C) on the working face. When the advance distance reaches the limit span $L_{1}$ of the basic roof, the key block $\mathrm{B}$ and the key block $\mathrm{C}$ revolve and sink, and the working face is pressed. With the advance of the working face, the basic roof breaks periodically. The basic roof of the working face in the lower section is the key block A. On the I-I section, the key block A, the key block B, and the key block $\mathrm{C}$ form a hinged structure, as shown in Figure 1(b).

In Figure 1, $m$ is the thickness of the coal seam, $h$ is the thickness of the direct roof, and $H$ is the basic roof thickness; $x_{0}$ is the fracture position of the key block B; $a$ is the width of the roadway; $b$ is the width of the roadside support; $L_{\mathrm{i}}$ is the limit span of the basic roof, means the first or periodic weighting length during the first or periodic weighting stage of basic roof; $L_{2}$ is the lateral span of key block B; $\theta$ is the rotation angle of the basic roof.

The remaining roadway along the goaf is located at the face end, and its basic roof is the key block B. The direct roof will produce a certain length of suspended roof due to the supporting effect of coal pillar, and its weight will be borne by the roadside support.

Lagging behind the working face for a certain distance, the key block B loses stability, rotates, and sinks, and then the direct roof collapses. The pressure and deformation of the roadway increase rapidly. The roadside support cannot prevent the subsidence of the basic roof, but it can control and reduce the direct roof separation and limit subsidence amount of the basic roof. It can be considered that the pressure appearance of roadway retaining along the goaf is mainly determined by the instability of key block B.

\subsection{Mechanical Parameters of Key Block B}

2.2.1. Lateral Span $L_{2}$ of Key Block B. According to the failure theory of plates, the expression of $L_{2}$ is derived by using the void principle [13].

At the first collapse of the base roof,

$$
L_{2}=\frac{L_{0}^{2}}{2 S}\left(\sqrt{1+3\left(\frac{S}{L_{0}}\right)^{2}}-1\right) .
$$

At the periodic collapse of the base roof,

$$
L_{2}=\frac{2 L_{1}^{2}}{17 S}\left(\sqrt{100+102\left(\frac{S}{L_{1}}\right)^{2}}-10\right)
$$

where $L_{0}$ and $L_{1}$ are the first and periodic weighting length of the basic roof, respectively.

2.2.2. The Fracture Position $x_{0}$ of the Key Block B. With the advance of the working face, the abutment pressure is generated in front of the coal wall, and part of the coal body enters the plastic state. When the pressure exceeds the strength of the coal body, the coal will be damaged and lose its supporting capacity. Since the bearing capacity of the coal in the plastic state is greatly reduced and extremely unstable, the subsidence and bending of the overlying rock beam cannot be prevented, which creates the conditions for the rock beam to break in front of the coal wall. According to the theory of elastic-plastic mechanics, the formula of the fracture position $x_{0}$ of the key block B is [14]

$$
x_{0}=\frac{m A}{2 \operatorname{tg} \phi_{0}} \ln \left(\frac{K \gamma H+\left(C_{0} / \operatorname{tg} \phi_{0}\right)}{\left(C_{0} / \operatorname{tg} \phi_{0}\right)+(P / A)}\right) \text {, }
$$

where $m$ is the mining height, $\phi_{0}$ is the internal friction angle of the coal body, $C_{0}$ is the cohesion in the coal body, $K$ is the stress concentration coefficient, $\gamma$ is the average volume force of the overburden, $\mathrm{MN} / \mathrm{m}^{3}, H$ is the buried depth, and $P$ is the support resistance of the coal side, $\mathrm{MPa}$.

\section{Pressure Relief Mechanism of Hydraulic Fracturing for Gob-Side Entry Retaining}

\subsection{Roadside Supporting Resistance}

3.1.1. Stress Analysis of Key Direct Roof. The direct roof is clamped by the basic roof and the coal body, assuming that the edge is a fixed-support boundary. The mechanical model of the direct roof is shown in Figure 2.

In Figure 2, $F_{M}$ is the resultant force of the basic roof to the direct roof; $F_{\mathrm{g}}$ is the gravity of the direct roof; $\sigma_{\mathrm{y}}$ is the support force of the coal body, MPa; $P$ is the support resistance of the coal side, $\mathrm{MPa} ; f_{\mathrm{s}}$ is the roof support resistance, $\mathrm{N} / \mathrm{m}$, and assumed to be a uniform load; $f_{\mathrm{d}}$ is the supporting force of the backfill and assumed to be a uniform load, $\mathrm{N} / \mathrm{m} ; M$ is the bending moment of the direct roof at point $\mathrm{O}$; and $F_{x}$ and $F_{y}$ are the boundary resistance.

Suppose the abscissa of the coal wall is 0 , the front of the coal wall is the positive direction of the $x$-axis, and the vertical direction is the $y$-axis, as seen in Figure 2, according to the limit equilibrium theory, the supporting force of the coal body can be obtained as [14]

$$
\sigma_{y}=\left(\frac{C_{0}}{\operatorname{tg} \phi_{0}}+\frac{P}{A}\right) e^{\left(2 \operatorname{tg} \phi_{0} / m A\right) x}-\frac{C_{0}}{\operatorname{tg} \phi_{0}} .
$$

The moments of $F_{\mathrm{M}}, F_{\mathrm{g}}, f_{\mathrm{s}}, f_{\mathrm{d}}$, and $\sigma_{y}$ to point $\mathrm{O}$ are 


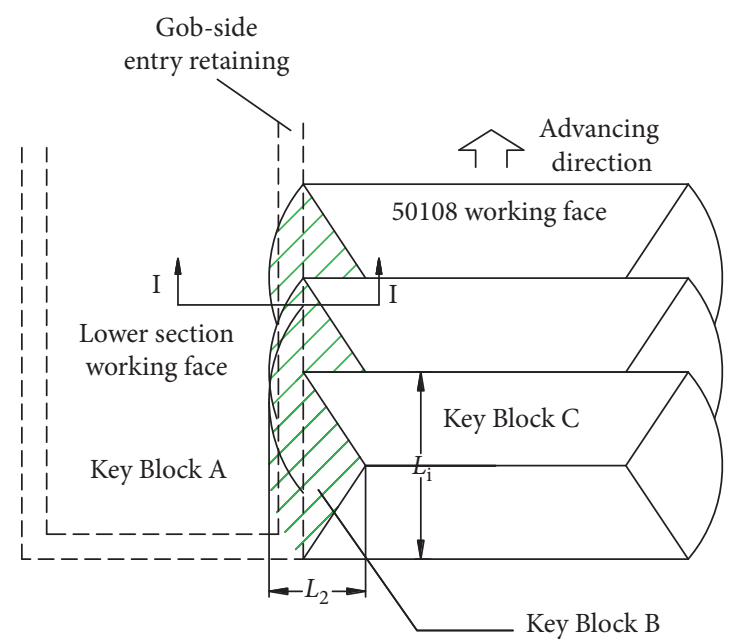

(a)

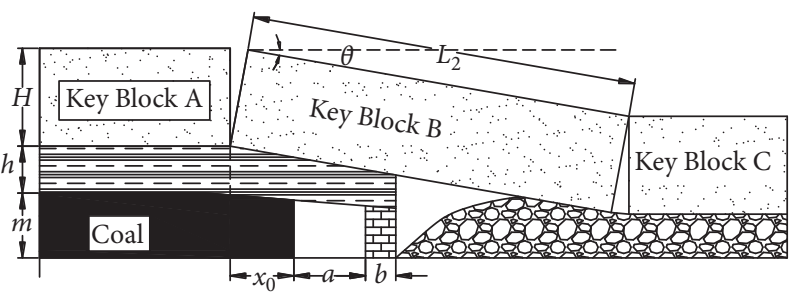

(b)

Figure 1: Basic roof failure mechanics model in gob-side entry retaining. (a) Basic roof failure form. (b) I-I section view.

$$
\left\{\begin{array}{l}
M_{F_{\mathrm{M}}}=\frac{F_{\mathrm{M}} x_{0}+a+b}{2}, \\
M_{F_{\mathrm{g}}}=\frac{F_{\mathrm{g}} x_{0}+a+b}{2}, \\
M_{f_{\mathrm{s}}}=f_{\mathrm{s}} a\left(x_{0}+\frac{a}{2}\right), \\
M_{f_{\mathrm{d}}}=f_{\mathrm{d}} b\left(x_{0}+a+\frac{b}{2}\right) \\
M_{\sigma_{y}}=\int_{0}^{x_{0}} \sigma_{y} L_{i}\left(x_{0}-x\right) \mathrm{d} x .
\end{array}\right.
$$

Due to the edge is a fixed-support boundary, then

$$
M=\frac{1}{6} \sigma_{t} h^{2} L_{i}
$$

According to the $\sum M_{O}=0$, we get

$$
M_{F_{\mathrm{M}}}=M_{f_{\mathrm{s}}}+M_{f_{\mathrm{d}}}+M_{\sigma_{y}}-\mathrm{M}_{\mathrm{F}_{\mathrm{g}}}+\mathrm{M} \text {. }
$$

3.1.2. Stress Analysis of Key Block B. The force analysis of the key block B is shown in Figure 3, where $M_{\mathrm{A}}$ and $M_{\mathrm{B}}$ are the residual bending moments of key block $\mathrm{B}$ at both ends, $T_{\mathrm{AB}}$ and $T_{\mathrm{CB}}$ are the horizontal thrust force of key block $\mathrm{A}$ and $\mathrm{C}$ to key block B, respectively, and $N_{\mathrm{AB}}$ and $N_{\mathrm{CB}}$ are shear stress of key block $\mathrm{A}$ and $\mathrm{C}$ to key block $\mathrm{B}$, respectively; $F_{\mathrm{G}}$ is the gravity of the key block $\mathrm{B} ; q$ is the pressure of the overlying soft rock layer, assuming a uniform load, ignoring the influence of the supporting force of the goaf gangue.

TCB can be obtained as [15]

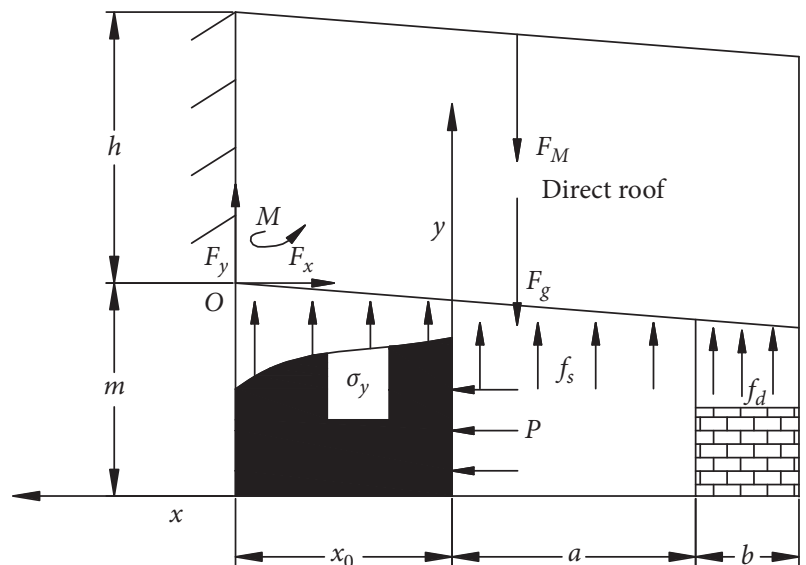

FIGURE 2: Direct roof force diagram.

$$
T_{\mathrm{CB}}=\frac{L_{2}\left(F_{\mathrm{G}}+q L_{2} \cos \theta\right) \cos \alpha}{H-\left(L_{2} \sin \theta / 2\right)},
$$

where $\alpha$ is the base angle of the curved triangle block.

The moments of $F_{\mathrm{M}}, F_{\mathrm{G}}, T_{\mathrm{CB}}, N_{\mathrm{CB}}$, and $q$ to point $\mathrm{A}$ are, respectively,

$$
\left\{\begin{aligned}
M_{F_{\mathrm{M}}} & =\frac{F_{\mathrm{M}} x_{0}+a+b}{2}, \\
M_{F_{\mathrm{G}}} & =F_{\mathrm{G}} \frac{1}{2}\left(\cos \theta L_{2}+\sin \theta H\right), \\
M_{T_{\mathrm{CB}}} & =T_{\mathrm{CB}}\left(\cos \theta H-\sin \theta L_{2}\right), \\
M_{N_{\mathrm{CB}}} & =N_{\mathrm{CB}}\left(\cos \theta L_{2}+\sin \theta H\right), \\
M_{q} & =\frac{q}{2} L_{2}^{2} \cos ^{2} \theta
\end{aligned}\right.
$$




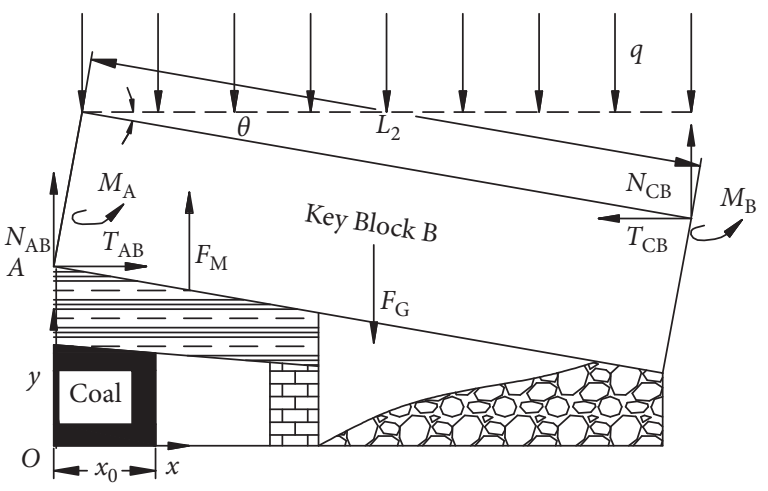

FIgURE 3: Force diagram of key block B.

According to the $\sum M_{A}=0$, we get

$$
M_{F_{\mathrm{M}}}=M_{F_{\mathrm{G}}}+M_{q}+M_{T_{\mathrm{CB}}}-M_{\mathrm{B}}-M_{\mathrm{A}}-M_{N_{\mathrm{CB}}} \text {. }
$$

Combine formula (10) and formula (7) to get

$$
\begin{aligned}
M_{f_{\mathrm{d}}}= & M_{F_{\mathrm{G}}}+M_{\mathrm{q}}+M_{T_{\mathrm{CB}}}+M_{F_{\mathrm{g}}}-M_{\mathrm{B}}-M_{\mathrm{A}}-M \\
& -M_{N_{\mathrm{CB}}}-M_{f_{\mathrm{s}}}-M_{\sigma_{y}}, \\
f_{\mathrm{d}}= & \frac{M_{f_{\mathrm{d}}}}{b\left(x_{0}+a+(b / 2)\right)} .
\end{aligned}
$$

3.2. Pressure Relief Mechanism of Hydraulic Fracturing. Hydraulic fracturing cuts off the cantilever length of the direct roof and reduces the pressure from the direct roof during normal propulsion.

It makes the direct roof collapse in time with the mining, fills the goaf better, and reduces the subsidence amount of the basic roof. At the same time, hydraulic fracturing cuts off the lateral cantilever length of the base top, causing the base roof to fall along the prefracture line, thus reducing the pressure from the base roof. Assuming that the rotation angle $\theta$ of the key block is constant, the mechanical model is shown in Figure 4.

In formula (11), $M_{\mathrm{B}}, M_{\mathrm{A}}, M, M_{f_{\mathrm{s}}}, M_{\sigma_{y}}$, and $M_{F_{\mathrm{g}}}$ can be regarded as constants, ignoring the influence of the shear force of key block $\mathrm{C}$ on key block B $\left(M_{N_{C B}}\right)$. Therefore, it is $M_{F_{\mathrm{G}}}, M_{T_{\mathrm{CB}}}$, and $M_{q}$ that play a decisive role in $F_{\mathrm{d}}$.

As can be seen from Figure 4, the key block B falls along the prefracture line and becomes two smaller blocks $B_{1}$ and $\mathrm{B}_{2}$. The length of the basic top suspension decreases from L2 to $\mathrm{L} 2^{\prime}$, which significantly reduced $M_{F_{\mathrm{G}}}, M_{T_{\mathrm{CB}}}$, and $M_{q}$, and their values were

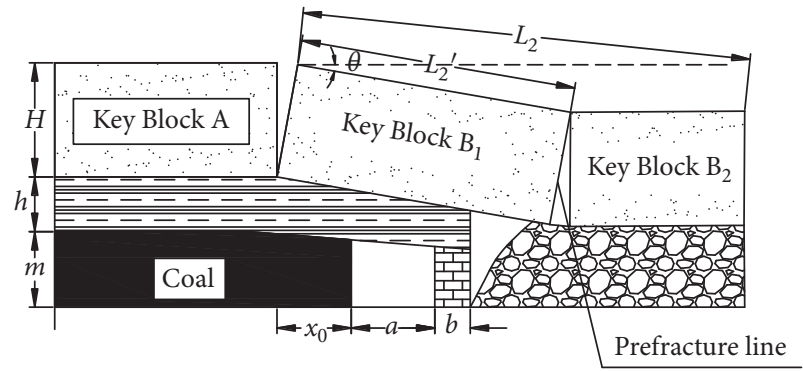

FIgUre 4: Hydraulic fracturing pressure relief mechanism.

$$
\left\{\begin{aligned}
M_{F_{\mathrm{G}}} & =\frac{H \gamma L_{i} L_{2}^{\prime}}{2} \frac{1}{2}\left(\cos \theta L_{2}^{\prime}+\sin \theta H\right), \\
M_{T_{C B}} & =\frac{L_{2}^{\prime}\left(F_{G}+q L_{2}^{\prime} \cos \theta\right) \cos \alpha}{H-\left(L_{2}^{\prime} \sin \theta / 2\right)} \cos \theta H-\sin \theta L_{2}^{\prime}, \\
M_{\mathrm{q}} & =\frac{q}{2} L_{2}^{2^{\prime}} \cos ^{2} \theta, \\
M_{\mathrm{q}} & =\frac{q}{2}{L_{2}^{2}}^{2^{\prime}} \cos ^{2} \theta .
\end{aligned}\right.
$$

Therefore, after the roof cutting of hydraulic fracturing, the roadside support resistance is significantly reduced.

\section{Field Test}

4.1. Basic Information of Test Site. The test site was selected in Hejiata Coal Mine, Shaanxi Province, and the hydraulic fracturing was carried out for the gob-side entry retaining in the haulage gateway of 50108 working face. The roadway mileage was $1950-1550 \mathrm{~m}$, the test length was $400 \mathrm{~m}$, the roadway width was $5.5 \mathrm{~m}$, and the height is $3.2 \mathrm{~m}$.

The coal thickness is $2.6-3.6 \mathrm{~m}$ with an average of $3 \mathrm{~m}$. Coal seam dip angle is $1-3^{\circ}$, near horizontal coal seam; the buried depth is $86-245 \mathrm{~m}$, a shallow coal seam. The working face length is $245 \mathrm{~m}$, and propulsion length is $4462 \mathrm{~m}$. The roof strata are shown in Figure 5.

\subsection{Directional Hydraulic Fracturing Scheme}

4.2.1. Ground Stress Measurement. The crack propagation direction is along the direction of maximum principal stress [3]. Therefore, the measurement of ground stress is very important for hydraulic fracturing. The maximum horizontal principal stress $\sigma_{\mathrm{H}}$, minimum horizontal principal stress $\sigma_{h}$, and vertical principal stress $\sigma_{v}$ were measured by 


\begin{tabular}{|c|c|c|c|c|}
\hline Columnar & Rock layer & $\begin{array}{c}\text { Thinckness } \\
(\mathrm{m})\end{array}$ & $\begin{array}{c}\text { Cumulative } \\
\text { thickness (m) }\end{array}$ & Roof type \\
\hline & Sandy mudstone & 3.7 & \multirow{3}{*}{28.6} & \multirow{3}{*}{$\begin{array}{l}\text { Composite } \\
\text { rock beam } \\
\text { basic roof } 2\end{array}$} \\
\hline & Gritstone & 1.6 & & \\
\hline & $\begin{array}{c}\text { Fine-grained } \\
\text { sandstone }\end{array}$ & 4.1 & & \\
\hline & Sandy mudstone & 0.48 & 19.2 & Soft layer \\
\hline & $5-1$ coal & 0.7 & 18.7 & Soft layer \\
\hline$\overline{\underline{\underline{\underline{\underline{E}}}}}$ & Sandy mudstone & 4.5 & 18 & Basic roof 1 \\
\hline & Siltstone & 6.95 & \multirow{3}{*}{13.5} & \multirow{3}{*}{ Direct roof } \\
\hline & $\begin{array}{l}\text { Medium-grained } \\
\text { sandstone }\end{array}$ & 0.95 & & \\
\hline$\therefore \therefore$ & Siltstone & 5.6 & & \\
\hline & $5-2$ coal & 3 & & Coal seam \\
\hline
\end{tabular}

FIGURE 5: Roof column.

type SSYY-56 hydraulic fracturing ground stress measuring instrument in the haulage gateway (see Table 1).

\subsubsection{Drilling Parameters and Layout}

(1) Cutting Angle ( $\alpha$ ). Hydraulic fracturing is carried out in advance of the working face. In order to prevent roadway roof from separating, a certain angle is required for drilling. The angle should not be too small or too large, when the angle is too small, the roof needs to overcome greater shear force, and when the angle is too large, the suspension length of the roof cantilever will be increased. Generally, the cutting angle $\alpha$ is $70-75^{\circ}$.

The drilling construction angle is set at $45^{\circ}$, so the cutting angle along the I-I section is $70^{\circ}$. Since the propagation direction of the crack is along the direction of the maximum principal stress, in order to facilitate make crack propagation easier, the direction of borehole layout should be perpendicular to the direction of the maximum principal stress as far as possible. According to the ground stress measurement result, the angle between the borehole and the roadway axis is set as $20^{\circ}$, as shown in Figure 6.

(2) Cutting Height. The cutting height $H_{\mathrm{m}}$ refers to the maximum vertical height of the borehole. First, $H_{\mathrm{m}}$ should be at least greater than the thickness of the direct roof, which can make the direct roof collapse in time and better fill goaf. The direct roof height is $\mathrm{m} /\left(K_{\mathrm{h}}-1\right)$, so $H_{\mathrm{m}} \geq m /\left(K_{\mathrm{h}}-1\right)$.

Secondly, according to the borehole column and the practical mine pressure theory [13], the number and location of the basic roof can be judged. The cutting height $H_{\mathrm{m}}$ should be the thickness of the basic roof. According to Figure 5, it can be seen that the second basic roof is $29 \mathrm{~m}$ above the coal seam, so the cutting height $H_{\mathrm{m}}$ is finally determined to be $29 \mathrm{~m}$, and the relationship between drilling height $H_{\mathrm{m}}$ and drilling depth $H_{\mathrm{d}}$ is $H_{\mathrm{m}}=H_{\mathrm{d}} \cos \alpha$.

(3) Drilling Spacing. Drilling spacing should ensure that the fractures produced by hydraulic fracturing between two holes can be connected. Field observation shows that when
TABLE 1: Ground stress measurement result.

\begin{tabular}{lllll}
\hline & \multicolumn{4}{c}{ Princple } \\
stress & & Direction $\left({ }^{\circ}\right)$ \\
& & $(\mathrm{MPa})$ & \\
& $\sigma_{\mathrm{H}}$ & $\sigma_{\mathrm{h}}$ & $\sigma_{\mathrm{v}}$ & \\
\hline 156.7 & 6.2 & 4.5 & 4.2 & $\mathrm{~N} 63.7^{\circ} \mathrm{W}$ \\
\hline
\end{tabular}

the horizontal spacing of boreholes is $10 \mathrm{~m}$, water flows out from the boreholes near the fracturing holes, indicating that the expansion range of fractures can reach about $20 \mathrm{~m}$. To ensure the roof-cutting effect, the horizontal spacing of boreholes on site is set at $10 \mathrm{~m}$, and the layout of boreholes is shown in Figure 6.

\subsubsection{Construction Techonology}

(1) Using a special drill bit to prefabricate transverse notch in the hard roof, that is equivalent to setting an artificial fracture: fracturing will cause stress concentration at the tip of the crack, which can effectively reduce the pressure required for crack production and make the crack expand along the direction of the notch at the initial stage.

(2) Sealing the hole: the inflatable straddle packer adopted for hole sealing ensures the stepwise fracturing in the hard strata. The fracturing process stopped at a distance of $8 \mathrm{~m}$ from the bore hole, and the fracturing is performed once every $3 \mathrm{~m}$, with each fracturing time of $20 \mathrm{~min}$.

(3) Fracturing: according to the elastic theory, the pressure required for fracture production is [16]

$$
p=3 \sigma_{\min }-\sigma_{\max }+\sigma_{t}
$$

$\sigma_{\min }$ and $\sigma_{\max }$ are the maximum and minimum ground stress, respectively; $\sigma_{t}$ is the uniaxial tensile strength of the rock, taking the value of $15 \mathrm{MPa}$. According to the ground stress measurement results in Table 1, the pressure required for crack production can be calculated as 20.7 MPa. Considering the pressure loss and a certain surplus coefficient, the rated pressure of the pump can be determined as $35 \mathrm{MPa}$.

\section{Data Analysis}

5.1. Hydraulic Fracturing Curve. As shown in Figure 7, during the fracturing process, the fracture propagation pressure is relatively constant, maintained at about $15 \mathrm{MPa}$. The fracturing curve is tightly jagged, which shows that fractures continue to propagate with nearly the same and relatively small size each time, and the fracture propagation effect is good.

5.2. Working Resistant of Face-End Support before and after Fracturing. Before and after hydraulic fracturing, the working resistant of face-end support is shown in Figure 8. It can be seen that the average pressure before fracturing is 


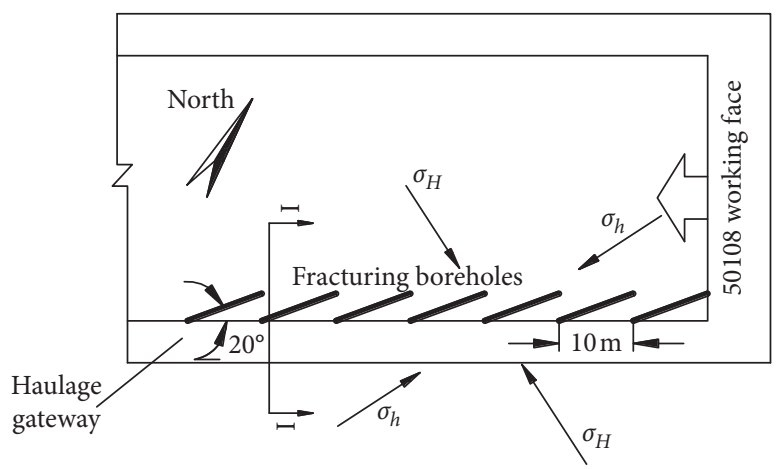

(a)

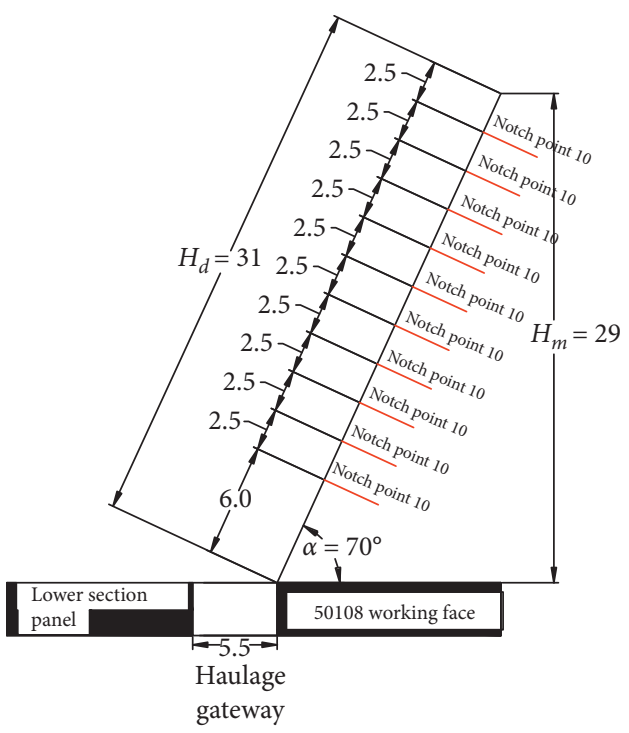

(b)

FIgURE 6: Drilling layout drawing. (a) Drilling layout. (b) I-I section.

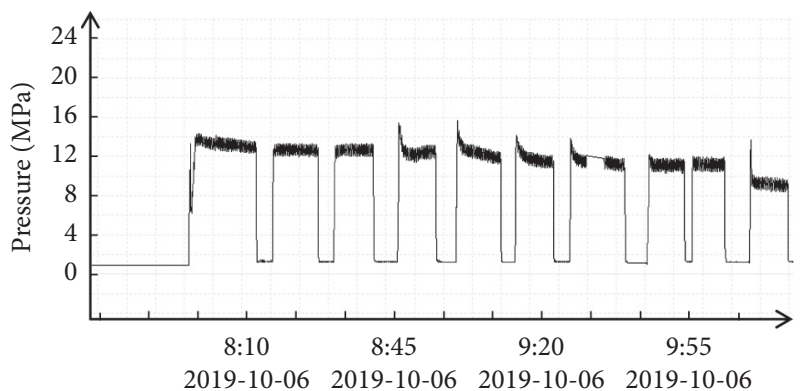

(a)

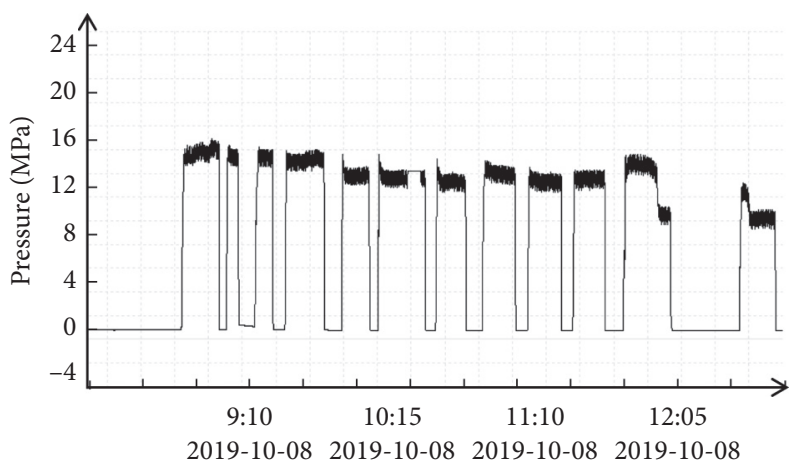

(b)

Figure 7: Hydraulic fracturing curve. (a) Borehole no. 27. (b) Borehole no. 28.

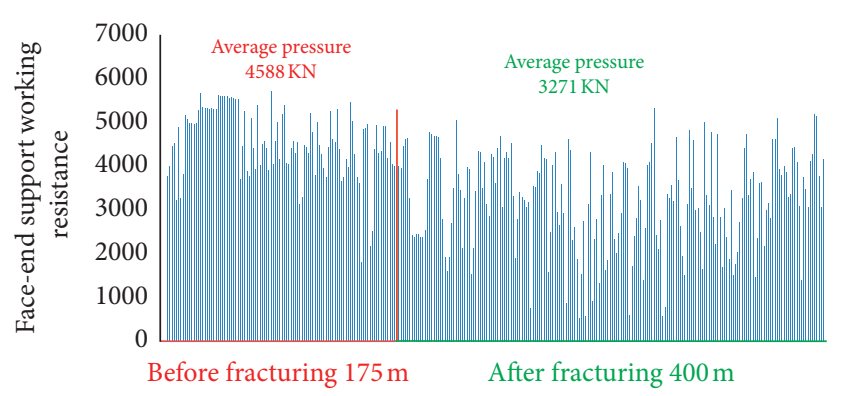

FIGURE 8: Working resistant of face-end support before and after fracturing.

$4588 \mathrm{KN}$, and after fracturing is $3271 \mathrm{KN}$; the reduction is $1317 \mathrm{KN}$, and the reduction rate is $29 \%$. It indicates that hydraulic fracturing effectively reduces the face-end pressure and improves the stress environment.
5.3. Effect of Gob-Side Entry Retaining. In the test section of gob-side entry retaining in 50108 working face, the deformation of the roadway and the bolt's force were monitored on the spot.

The force of the bolt is shown in Figure 9. The results show that the bolt stress $20 \mathrm{~m}$ ahead of the working face starts to increase, $10 \mathrm{~m}-40 \mathrm{~m}$ behind the working face, the stress increases rapidly, and $80 \mathrm{~m}$ behind the working face the stress gradually stabilizes. The overall force of the bolt is relatively small, and the maximum value does not exceed $60 \mathrm{kN}$, which is far from the supporting ability $120 \mathrm{kN}$ of the bolt.

Through site monitoring, the displacement of the roof and floor of the roadway retaining along the goaf is $\leq 160 \mathrm{~mm}$. $100 \mathrm{~m}$ behind the working face, the effect diagram of gob-side entry retaining is shown in Figure 10.

Therefore, the application of hydraulic fracturing for the gob-side entry retaining can significantly improve the stress 


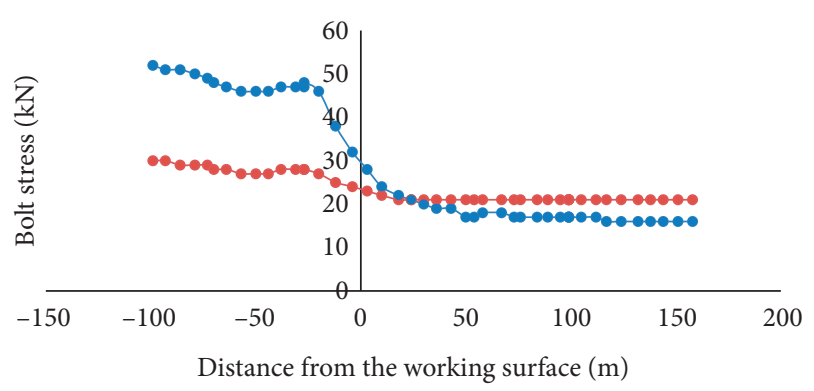

$\rightarrow$ Bolt no.1

$\rightarrow$ Bolt no.2

FIgURE 9: Bolt stress monitoring.

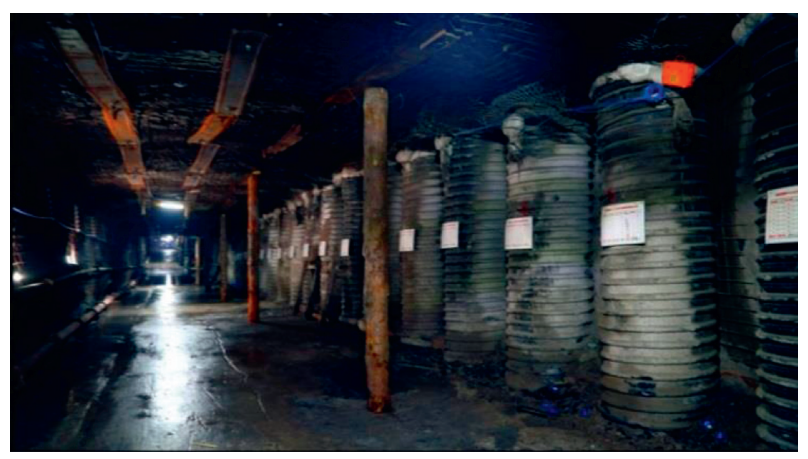

Figure 10: The effect of gob-side entry retaining $100 \mathrm{~m}$ behind the working face.

environment of the face end and reduce the roof pressure and roadway deformation, and the application effect is good.

\section{Conclusion}

(1) It is the moments of gravity $F_{\mathrm{G}}$ of the curved triangular roof plate, the pressure $q$ of the overlying soft rock, and the transverse force $T_{\mathrm{CB}}$ of the "voussoir beam" to the left endpoint of the triangular block, that is $M_{F_{\mathrm{G}}}, M_{T_{\mathrm{CB}}}$, and $M_{q}$, which determines the roadside supporting resistance. Hydraulic fracturing reduces the lateral cantilever length of the basic roof, thus greatly reducing the values of $M_{F_{\mathrm{C}}}, M_{T_{\mathrm{CB}}}$, and $M_{q}$ and can significantly reduce the roadside supporting resistance.

(2) Hydraulic fracturing can significantly improve the stress environment of the face end, reduce the amount of roadway deformation, and achieve good application results. In the field test in Hejiata Coal Mine, the resistance of the end support decreases by $29 \%$, and the maximum displacement of the roof and floor is $160 \mathrm{~mm}$.

\section{Data Availability}

The data used to support the findings of this study are included within the article.

\section{Conflicts of Interest}

The authors declare that they have no conflicts of interest.

\section{References}

[1] C.-L. Han, N. Zhang, B.-Y. Li, G.-Y. Si, and X.-G. Zheng, "Pressure relief and structure stability mechanism of hard roof for gob-side entry retaining," Journal of Central South University, vol. 22, no. 11, pp. 4445-4455, 2015.

[2] P. Guo, X. Zhang, Y. Peng, M. He, C. Ma, and D. Sun, "Research on deformation characteristic and stability control of surrounding rock during gob-side entry retaining," Geotechnical and Geological Engineering, vol. 38, no. 3, pp. 2887-2902, 2020.

[3] C.-Q. Zhu, X.-X. Miao, and Z. Liu, "Mechanical analysis on deformation of surrounding rock with road-in packing of gob-side entry retaining in fully-mechanized sub-level caving face," Journal of Coal Science and Engineering (China), vol. 14, no. 1, pp. 24-28, 2008.

[4] X. Yang, L. Hou, H. Xue et al., "Pressure distribution and deformation control of gob-side entry retaining formed by roof cutting influenced by abandoned roadways," Geotechnical and Geological Engineering, vol. 39, pp. 2533-2545, 2020.

[5] Z. Guangchao, Z. Chuanwei, C. Miao et al., "Ground response of entries driven adjacent to a retreating longwall panel," International Journal of Rock Mechanics and Mining Sciences, vol. 138, no. 11, Article ID 104630, 2021.

[6] X. Yang, C. Liu, Y. Ji, X. Zhang, and S. Wang, "Research on roof cutting and pressure releasing technology of directional fracture blasting in dynamic pressure roadway," Geotechnical and Geological Engineering, vol. 37, no. 3, pp. 1555-1567, 2019.

[7] X. Yang, W. Mao, E. Wang, Y. Sun, J. Wang, and M. He, "Mechanism and control methods of roof deformations in gob-side entry retention by roof cutting under medium-thick coal seams," Geotechnical and Geological Engineering, vol. 38, no. 1, pp. 265-282, 2020.

[8] Z. Han, Y. Huang, J. Li, S. Zayzay, and H. Gao, "Study on key parameters of roof cutting and pressure release in mediumthickness coal seam," Geotechnical and Geological Engineering, vol. 37, no. 4, pp. 3413-3422, 2019.

[9] Y. J. Feng and H. P. Kang, "Test on hard and stable roof control by means of directional hydraulic fracturing in coal mine," Chinese Journal of Rock Mechanics and Engineering, vol. 31, no. 6, pp. 1148-1155, 2012.

[10] S. H. Yan, Y. Ning, L. J. Kang et al., "The mechanism and experimental research on the treatment of hard roof by hydraulic fracturing," Journal of China Coal Society, vol. 1, pp. 34-37, 2000.

[11] W. Li, Y. Liu, X. Yao, J. Chu, X. Chen, and Z. Tan, "Study on breakdown pressure in hydraulic fracturing process of hard rock based on numerical simulation," Geotechnical and Geological Engineering, vol. 39, pp. 909-917, 2020.

[12] M. G. Qian and P. W. Shi, "Mine pressure and ground control," pp. 59-60, China University of Ming and Technology Press, Xuzhou, China, 2012, Thesis.

[13] Z. Q. Song, "Practical mine pressure control," pp. 94-95, China University of Ming and Technology press, Xuzhou, China, 1988, Thesis.

[14] C. J. Hou and N. J. Ma, "Discussion on the stress and limit equilibrium zone of the two sides of coal seam in the roadway," Journal of china Coal Society, vol. 4, pp. 21-29, 1989. 
[15] J. B. Bai, "Surrounding rock control of roadway driving along goaf," pp. 22-25, China University of Ming and Technology press, Xuzhou, China, 2006, Thesis.

[16] C. H. New, Mechanics of Hydraulic Fracturing, pp. 2-4, Gulf Publishing Company, Houston, TX, USA, 1997. 